03,05,09, 12

\title{
Повышение рабочей температуры спиновых светоизлучающих диодов (Ga,Mn)As/GaAs путем постростовых воздействий
}

\author{
(C) Е.И. Малышева ${ }^{1}$, М.В. Дорохин ${ }^{1}$, Ю.А. Данилов ${ }^{1}$, А.Е. Парафрин ${ }^{2}$, М.В. Ведь ${ }^{1}$, \\ А.В. Кудрин ${ }^{1}$, А.В. Здоровейщев ${ }^{1}$ \\ ${ }^{1}$ Научно-исследовательский фризико-технический институт \\ Нижегородского государственного университета им. Н.И. Лобачевского, \\ Нижний Новгород, Россия \\ ${ }^{2}$ Институт физики микроструктур РАН, филиал ФИЦ ИПФ РАН, \\ Нижний Новгород, Россия \\ E-mail: malysheva@phys.unn.ru
}

\begin{abstract}
Сформированы и исследованы спиновые светоизлучающие диоды на основе гетероструктур InGaAs/GaAs, содержащие ферромагнитные слои ( $\mathrm{Ga}, \mathrm{Mn}) \mathrm{As}$. Для повышения рабочей температуры спинового светоизлучающего диода поверхность структур перед нанесением металлических омических контактов подвергалась импульсному лазерному отжигу. Во внешнем магнитном поле сформированные диоды испускают циркулярно-поляризованное электролюминесцентное излучение. Получено повышение температуры регистрации циркулярно-поляризованной люминесценции с $30 \mathrm{~K}$ для исходной структуры до $110 \mathrm{~K}$ для структуры, подвергнутой лазерному отжигу. Полученный эффект связывается с повышением температуры Кюри $(\mathrm{Ga}, \mathrm{Mn}) \mathrm{As}$ в результате лазерного воздействия.
\end{abstract}

Работа выполнена в рамках проектной части госзадания Минобрнауки России (№ 8.1751.2017/ПЧ), при поддержке РФФИ (17-37-80008 мол_эв_а) и стипендии Президента РФ (СП-2450.2018.5).

DOI: $10.21883 /$ FTT.2018.11.46654.10NN

\section{1. Введение}

Спиновые светоизлучающие диоды (ССИД) с инжектором в виде слоев разбавленных магнитных полупроводников представляют интерес с точки зрения интеграции в оптоэлектронные микросхемы [1]. Перспективным методом получения таких диодов является газофазная эпитаксия из металлорганических соединений (ГФЭ MOC) в сочетании с импульсным лазерным нанесением (ИЛН). Ранее нами сообщалось о формировании структур спиновых светоизлучающих диодов, содержащих слои $(\mathrm{Ga}, \mathrm{Mn}) \mathrm{As}$, и получении низкотемпературной циркулярно-поляризованной люминесценции [2,3]. Ограничением ростового метода, использованного нами в [2,3], является низкое значение температуры Кюри слоя $(\mathrm{Ga}, \mathrm{Mn}) \mathrm{As}$, который формируется импульсным лазерным нанесением. Это ограничение существенно снижает рабочие температуры спинового светоизлучающего диода (до величины $\sim 30 \mathrm{~K}$ ) за счет понижения эффективности спиновой инжекции и, соответственно, значения степени циркулярной поляризации в области перехода ферромагнетик/парамагнетик [2,3]. В работе [4] сообщалось, что отжиг слоев (Ga,Mn)As, сформированных методом ИЛН, импульсным эксимерным лазером позволяет существенно повысить температуру Кюри (до уровня аналогов, полученных методом молекулярнолучевой эпитаксии [5]). В данной работе рассмотрено влияние отжига на свойства спиновых светоизлучающих диодов, содержащих подобные [2,3] слои (Ga,Mn)As. Показано, что применение импульсного лазерного отжига поверхности ССИД позволяет сместить точку Кюри (Ga,Mn)As инжектора до температуры $\sim 110 \mathrm{~K}$, и, таким образом, поднять рабочую температуру спинового светоизлучающего диода.

\section{2. Методика эксперимента}

Структуры сформированы комбинированным методом МОС-гидридной эпитаксии (МОСГЭ) в сочетании с импульсным лазерным нанесением (ИЛН) [2,3,6]. Было сформировано два типа структур. Первый тип (структура A) - представляет собой эпитаксиальные гетероструктуры светоизлучающих диодов (СИД) для исследований в режиме электролюминесценции, сформированные на подложках $p$-GaAs. Последовательно выращивались следующие слои: буферный слой $p$-GaAs, квантовая яма $\operatorname{In}_{x} \mathrm{Ga}_{1-x} \mathrm{As}: \mathrm{C}$ (концентрация дырок $p \approx 8 \cdot 10^{17} \mathrm{~cm}^{-3}$, ширина $\left.d_{\mathrm{QW}}=16 \mathrm{~nm}\right)$, слой $n-$ GaAs с градиентным легированием толщиной $90 \mathrm{~nm}$ и сильнолегированный $n^{++}-$слой толщиной $30 \mathrm{~nm}$ $\left(n \approx 10^{19} \mathrm{~cm}^{-3}\right)$. Затем при температуре $340^{\circ} \mathrm{C}$ методом лазерного распыления $\mathrm{Mn}$ и $\mathrm{GaAs}$ мишеней был выращен слой $(\mathrm{Ga}, \mathrm{Mn}) \mathrm{As}$ толщиной $90 \mathrm{~nm}$. Второй тип структур (структура В) предназначен для исследований гальваномагнитных явлений и представляет собой аналогичный слой (Ga,Mn)As толщиной $90 \mathrm{~nm}$, выращенный на подложке $i$-GaAs. Сформированные образцы подвергались воздействию импульсного лазерного отжига, выполненного с применением эксимерного лазера LPX-200, работающего на длине волны $248 \mathrm{~nm}$, имеющего длительность импульса $\sim 30 \mathrm{~ns}$, плотность энергии в импульсе до $290 \mathrm{~mJ} / \mathrm{cm}^{2}$ [4]. Было использовано три режима лазерного отжига, отличавшихся энергией лазерного воздействия, а именно, отжиги с энергиями 160 , 


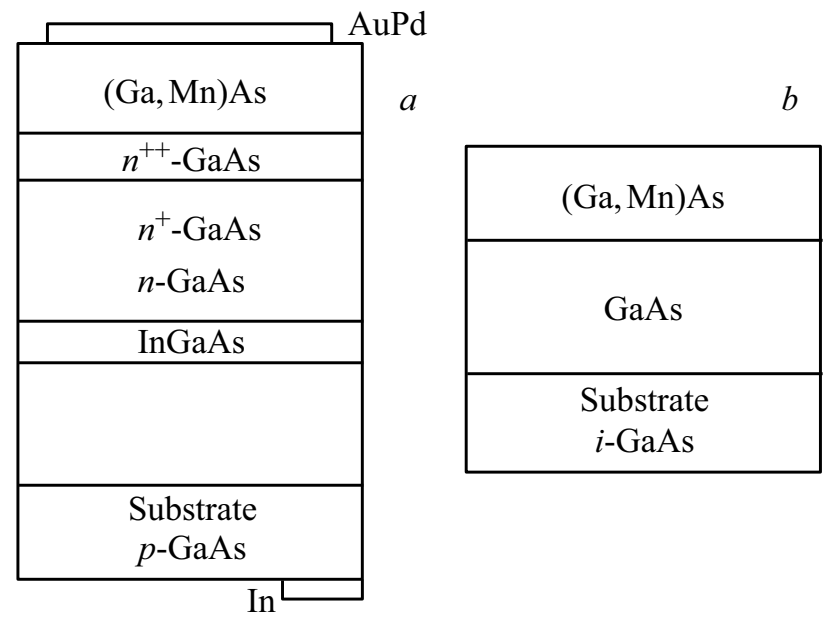

Рис. 1. Схемы исследованных структур: $a-$ светоизлучающий диод $(\mathrm{Ga}, \mathrm{Mn}) \mathrm{As} / n^{+}-\mathrm{GaAs} / n-\mathrm{GaAs} / \mathrm{InGaAs}$ (структуpa A), сформированный на подложке $p$-GaAs, $b$ - структура $\mathrm{B}$, сформированная на подложке $i$-GaAs.

260 и $290 \mathrm{~mJ} / \mathrm{cm}^{2}$. Лазерный пучок расфокусирован на площадь $1 \mathrm{~cm}^{2}$. Также исследовались исходные структуры, не подвергнутые лазерному отжигу. Схемы образцов представлены на рис. 1.

Для изучения свойств слоя $(\mathrm{Ga}, \mathrm{Mn}) \mathrm{As}$, подвергнутого лазерному отжигу, было проведено исследование морфологии поверхности структур на атомно-силовом микроскопе (ACM) NT-MDT Solver Pro в неконтактном режиме.

Для формирования диодов на поверхность образцов наносился омический $\mathrm{PdAu}$ контакт методом электронно-лучевого испарения в вакууме. Методами фотолитографии и химического травления изготавливали меза-структуры диаметром $500 \mu \mathrm{m}$.

На диодах проведены исследования электролюминесценции (ЭЛ), циркулярной поляризации ЭЛ в диапазоне температур 10-300 K. Магнитное поле направлено перпендикулярно поверхности структур. Степень циркулярной поляризации ЭЛ $\left(P_{\mathrm{EL}}\right)$ оценивалась по формуле:

$$
P_{\mathrm{EL}}=\left(\left(I\left(\sigma^{+}\right)-I\left(\sigma^{-}\right)\right) /\left(I\left(\sigma^{+}\right)+I\left(\sigma^{-}\right)\right)\right) \cdot 100 \%,
$$

где $I\left(\sigma^{+}\right), I\left(\sigma^{-}\right)$- относительные интенсивности ЭЛ, измеренные для света, поляризованного по левому и по правому кругу.

На контрольных структурах (В) проводились измерения магнитополевых зависимостей слоевого сопротивления в диапазоне температур $10-120 \mathrm{~K}$, что позволило оценить влияние лазерного отжига на гальваномагнитные свойства слоя $(\mathrm{Ga}, \mathrm{Mn}) \mathrm{As}$.

\section{3. Экспериментальные результаты и обсуждение}

Характерной особенностью процесса лазерного отжига является неоднородность лазерного пучка: энергия лазерного импульса в центре выше энергии импульса по краям лазерного пучка, следовательно, воздействие его на образец также неоднородно. На рис. 2 представлена топография поверхности образцов, подвергнутых отжигу с энергиями 160, 260 и $290 \mathrm{~mJ} / \mathrm{cm}^{2}$ : участков из центральной части образца (рис. $2, c, e, f$ ) и с периферии (рис. 2, $b, d)$, а также исходного образца (рис. 2,a). Исходная поверхность структуры характеризуется среднеквадратичной высотой неровностей равной $\sim 22 \mathrm{~nm}$, латеральным размером неровностей $\sim 100 \mathrm{~nm}$. Воздействие лазера на поверхность существенно модифицирует ее топографию. Минимальное изменение зарегистрировано на периферии образца, отожженного лазером с энергией $160 \mathrm{~mJ} / \mathrm{cm}^{2}$ (рис. 2, $b$ ). При повышении интенсивности воздействия на поверхности формируются крупные кластеры низкой плотности, а также гантелеобразные кластеры менышего размера. Реконструкция поверхности является характерной особенностью импульсного лазерного отжига [7]. Интересным экспериментальным фактом представляется подобие топографии поверхности исходного образца и периферии образца, отожженного при энергии $160 \mathrm{~mJ} / \mathrm{cm}^{2}$ (рис. 2, $a$ и $b$ соответственно), а также топографии центра образца с отжигом при энергии $160 \mathrm{~mJ} / \mathrm{cm}^{2}$ и участка образца с периферии, подвергнутого отжигу при энергии $290 \mathrm{~mJ} / \mathrm{cm}^{2}$ (рис. 2, $c$ и $d$ соответственно). Это свидетельствует о близких значениях плотности мощности лазерного воздействия для указанных участков (то есть, в первом случае воздействие лазерного пучка с энергией $160 \mathrm{~mJ} / \mathrm{cm}^{2}$ на периферию структуры мало). Отметим, что для исследований циркулярной поляризации электролюминесценции были выбраны диоды, расположенные в центральной части образца.

Анализ изменения магнитных свойств слоев в результате импульсного лазерного отжига был выполнен по результатам гальваномагнитных измерений, проведенных на структурах В [4]. На рис. 3 представлены зависимости слоевого сопротивления от магнитного поля для структуры В, подвергнутой отжигу лазера с энергией $290 \mathrm{~mJ} / \mathrm{cm}^{2}$ (рис. 3, $b$ ) и исходной части структуры В (рис. $3, a$ ), измеренных в диапазоне температур $13-80 \mathrm{~K}$. При минимальной температуре измерений $(13 \mathrm{~K})$ на обоих графиках наблюдаются участки положительного магнетосопротивления, причем обе зависимости образуют замкнутую петлю гистерезиса. По мере увеличения температуры измерений амплитуда магнетосопротивления уменьшается, а петля гистерезиса сужается. При температуре, равной $40 \mathrm{~K}$ для исходной структуры и $80 \mathrm{~K}$ для отожженной структуры, участок положительного магнетосопротивления и петля гистерезиса пропадают. Указанное значение оценивается как точка Кюри слоя $(\mathrm{Ga}, \mathrm{Mn}) \mathrm{As}$. Отметим, что в результате отжига оценочное значение температуры Кюри выросло с 40 до 80 К. Дополнительным подтверждением смещения точки Кюри в область более высоких температур в результате отжига является наличие нелинейной зависимости сопротивления Холла (аномального эффекта Холла) для отожженного образца (вставка к рис. 3, a, кривая 2) [8]. 

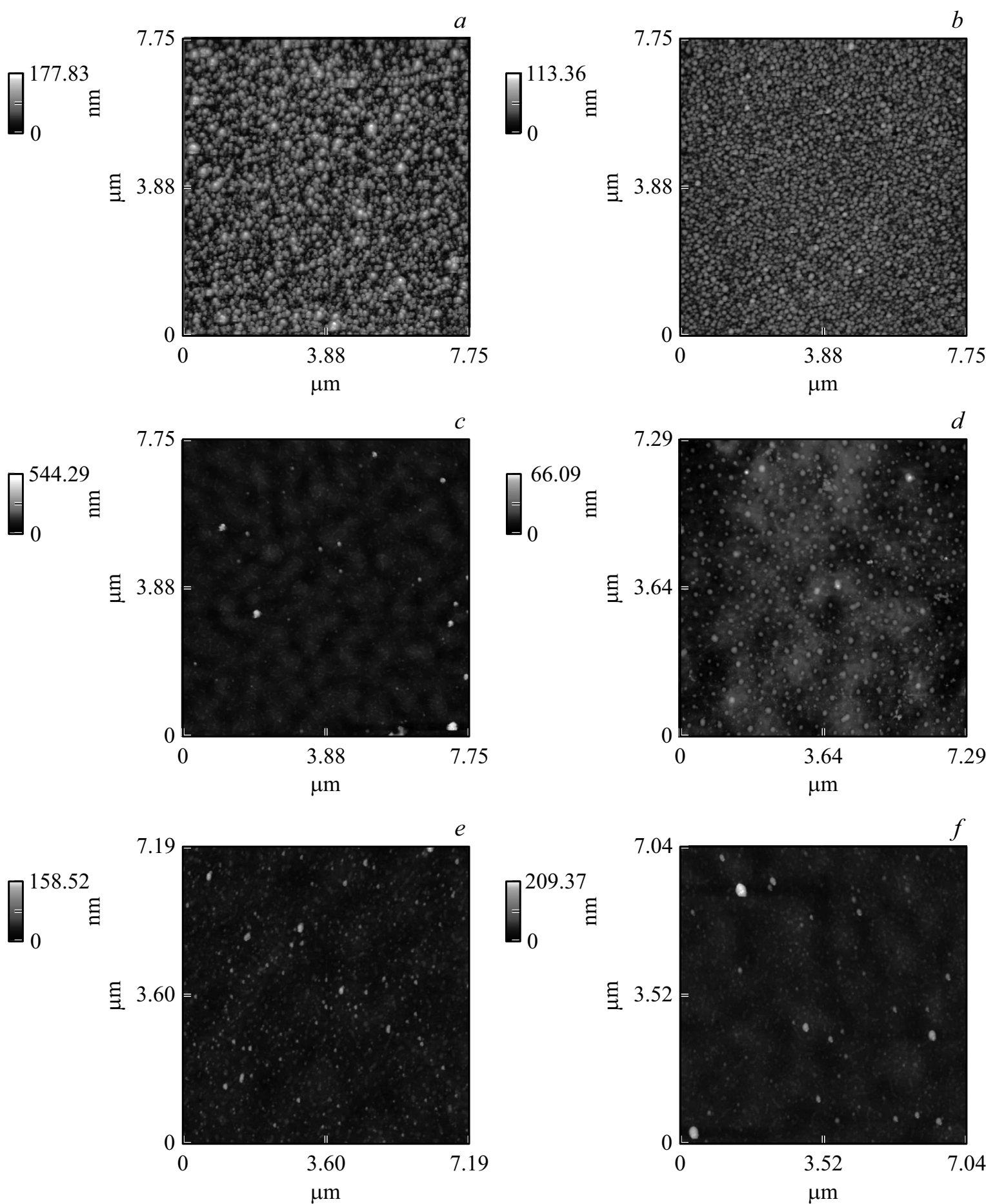

Рис. 2. Топография поверхности структуры спинового светоизлучающего диода с поверхностным слоем (Ga,Mn)As (a), a также той же структуры, подвергнутой импульсному лазерному отжигу: $(b)-160 \mathrm{~mJ} / \mathrm{cm}^{2}$ (на периферии лазерного пучка); (c) $160 \mathrm{~mJ} / \mathrm{cm}^{2}$ (в центре лазерного пучка); (d) $290 \mathrm{~mJ} / \mathrm{cm}^{2}$ (на периферии лазерного пучка); (e) $260 \mathrm{~mJ} / \mathrm{cm}^{2}$ (в центре лазерного пучка); $(f) 290 \mathrm{~mJ} / \mathrm{cm}^{2}$ (в центре лазерного пучка).

Для исходной структуры магнитополевая зависимость сопротивления Холла может быть описана линейной функцией (вставка к рис. $3, a$, кривая 1 ).

На рис. 4 представлены магнитополевые зависимости степени циркулярной поляризации электролюминесценции, измеренные в диапазоне температур $10-120 \mathrm{~K}$ для исходного (рис. $4, a)$ и отожженного (рис. $4, b)$ образцов. В обоих случаях кривые, измеренные при $13 \mathrm{~K}$, являются нелинейной функцией магнитного поля. На нелинейных зависимостях $P_{\mathrm{EL}}(B)$ наблюдается два участка: участок быстрого изменения $P_{\mathrm{EL}}$ в диапазоне магнитных полей $0-0.1 \mathrm{~T}$ и участок ,медленного“ увеличения 

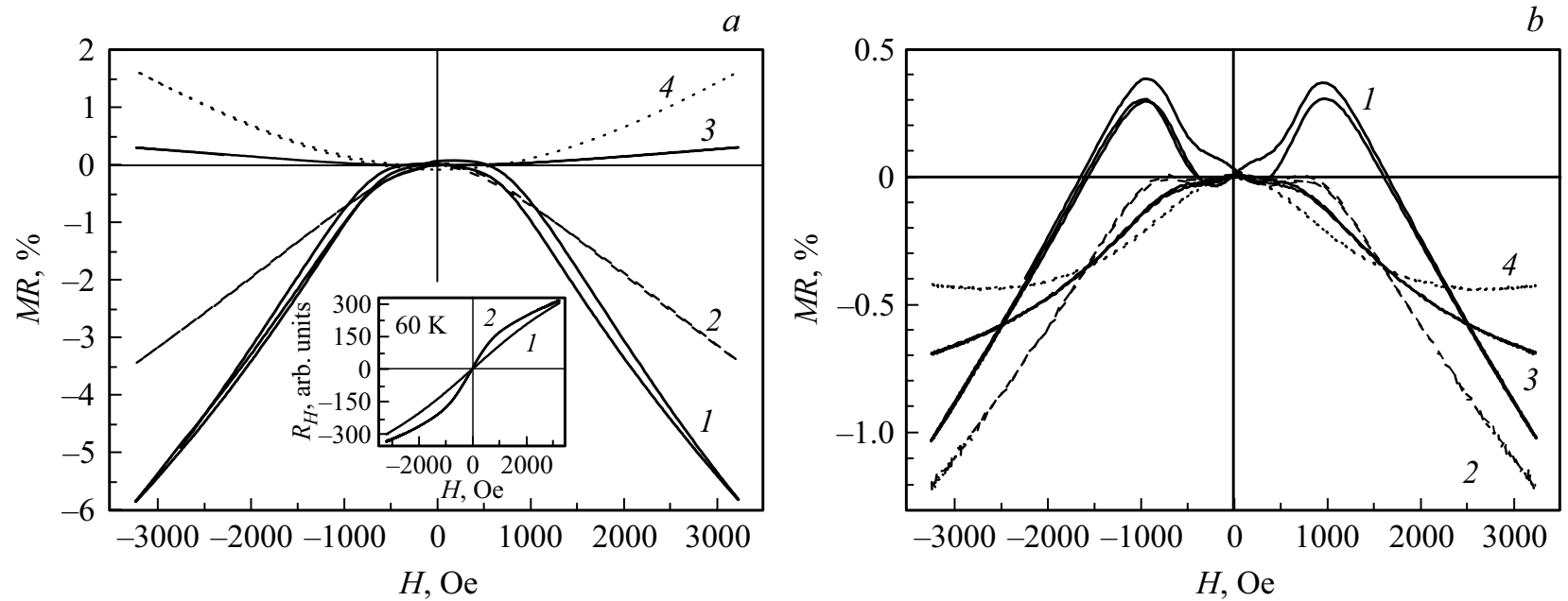

Рис. 3. Магнитополевые зависимости слоевого сопротивления структуры ( $\mathrm{Ga}, \mathrm{Mn}) \mathrm{As} / \mathrm{i}-\mathrm{GaAs}$, измеренные при различных температурах, для исходной структуры $(a)$, и структуры, подвергнутой отжигу лазером с энергией $290 \mathrm{~mJ} / \mathrm{cm}^{2}(b)$. Температуры измерений: $13 \mathrm{~K}$ (кривая 1 ), $40 \mathrm{~K}$ (кривая 2), $60 \mathrm{~K}$ (кривая 3), $80 \mathrm{~K}$ (кривая 4). На вставке к рис. 3, $a$ показаны магнитополевые зависимости сопротивления Холла, измеренные при температуре $60 \mathrm{~K}$ для исходной структуры $(1)$ и отожженной с энергией $290 \mathrm{~mJ} / \mathrm{cm}^{2}(2)$.
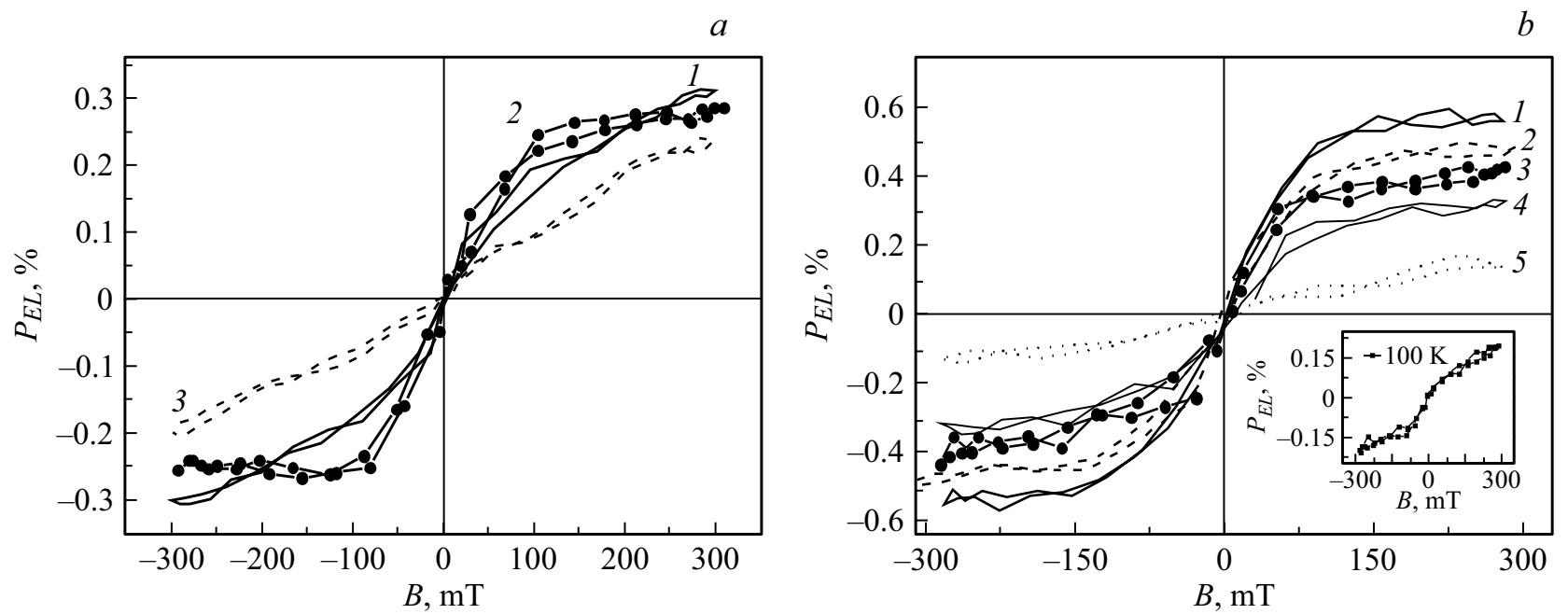

Рис. 4. Магнитополевые зависимости степени циркулярной поляризации электролюминесценции: $a$ ) исходной структуры в диапазоне температур $13-30 \mathrm{~K}$ (кривая $1-13 \mathrm{~K}$; кривая $2-20 \mathrm{~K}$, кривая $3-30 \mathrm{~K}$ ) и $b$ ) структуры, подвергнутой лазерному отжигу, в диапазоне температур $14-120 \mathrm{~K}$ (кривая $1-13 \mathrm{~K}$, кривая $2-40 \mathrm{~K}$, кривая $3-60 \mathrm{~K}$, кривая $4-80 \mathrm{~K}$, кривая $5-110 \mathrm{~K})$. На вставке показана магнитополевая зависимость степени поляризации, измеренная для той же структуры при температуре $100 \mathrm{~K}$.

степени поляризации в полях $0.1-0.3 \mathrm{~T}$. На участке „медленного“ увеличения степени поляризации $P_{\mathrm{EL}}(B)$ может быть аппроксимирована линейной функцией. Значение $P_{\mathrm{EL}}$ с достаточной степенью точности может быть представлено в виде суммы двух слагаемых:

$$
P_{\mathrm{EL}}=P_{\mathrm{EL}}^{\mathrm{FM}}+P_{\mathrm{EL}}^{\mathrm{Z}},
$$

где $P_{\mathrm{EL}}^{\mathrm{FM}}-$ слагаемое, связанное с инжекцией спинполяризованных электронов, $P_{\mathrm{EL}}^{Z}-$ слагаемое, обусловленное зеемановским расщеплением в магнитном поле уровней размерного квантования в квантовой яме.
Отметим повышение степени циркулярной поляризации в результате отжига (рис. $4, a, b$, кривая 1 ).

В структурах без лазерного отжига при увеличении температуры измерений значение степени циркулярной поляризации уменьшается, и при температуре $30 \mathrm{~K}$ зависимость $P_{\mathrm{EL}}(B)$ становится линейной. В этой точке и для более высоких температур на зависимости $P_{\mathrm{EL}}(B)$ имеет место монотонное увеличение степени циркулярной поляризации с ростом магнитного поля, которое может быть описано линейной функцией и которое, по-видимому, обусловлено зеемановским расщеплением уровней квантовой ямы в магнитном поле $P_{\mathrm{EL}}^{Z}$. В струк- 


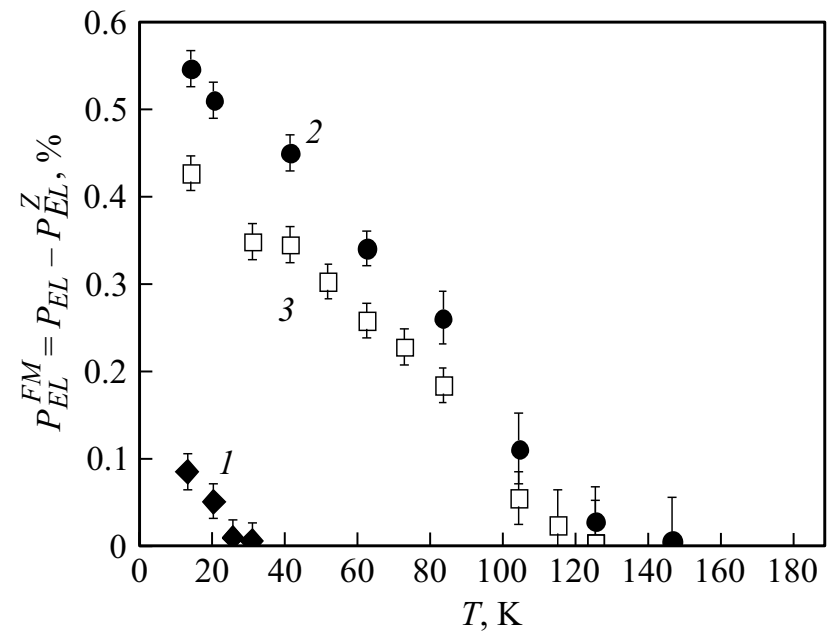

Рис. 5. Температурные зависимости степени циркулярной поляризации электролюминесценции, измеренные в магнитном поле $280 \mathrm{mT}$ для спиновых светоизлучающих диодов на основе исходной структуры ( 1 - закрытые ромбы), структуры, подвергнутой отжигу лазером с энергией $260 \mathrm{~mJ} / \mathrm{cm}^{2}(2-$ закрытые кружки), структуры, подвергнутой отжигу лазером с энергией $290 \mathrm{~mJ} / \mathrm{cm}^{2}$ (3 - открытые квадраты).

турах, подвергнутых лазерному отжигу, при повышении температуры измерений значение степени циркулярной поляризации уменьшается медленнее по сравнению с исходным образцом, а зависимость становится линейной при температуре $110 \mathrm{~K}$.

Наиболее наглядно эффект повышения рабочей температуры ССИД в результате лазерного отжига может быть продемонстрирован на температурных зависимостях степени поляризации, измеренных при введении диода в магнитное поле $\sim 280 \mathrm{mT}$, представленных на рис. 5. Данные представлены за вычетом компоненты, связанной с зеемановским расщеплением уровней $P_{\mathrm{EL}}^{Z}$.

Для всех исследованных структур с ростом температуры значение степени циркулярной поляризации уменьшается. Для структур, подвергнутых лазерному отжигу с энергиями 260 и $290 \mathrm{~mJ} / \mathrm{cm}^{2}$, область падения степени поляризации затянута по сравнению с исходной структурой, а значение $P_{\mathrm{EL}}^{\mathrm{FM}}$ обращается в нуль при температуре $\sim 110-120 \mathrm{~K}$. Зависимости $P_{\mathrm{EL}}^{\mathrm{FM}}(T)$ подобны с учетом погрешности измерений. Можно отметить несколько более высокое значение степени поляризации для структуры, отожженной при $260 \mathrm{~mJ} / \mathrm{cm}^{2}$, по сравнению с другими мощностями отжига. Для структуры, подвергнутой отжигу с энергией $160 \mathrm{~mJ} / \mathrm{cm}^{2}$, принципиального изменения степени поляризации и диапазона рабочих температур не зарегистрировано. Зависимость $P_{\mathrm{EL}}^{\mathrm{FM}}(T)$ для указанной структуры в пределах погрешности совпадает с зависимостью для исходной структуры (рис. 4, кривая 1). По-видимому, указанной энергии лазерного отжига недостаточно для того, чтобы оказать существенное воздействие на свойства пленки (Ga,Mn)As.
Повышение диапазона рабочих температур диодов на основе структур, подвергнутых лазерному отжигу, мы связываем с повышением температуры Кюри ферромагнитного инжектора (Ga,Mn)As. Согласно результатов измерений циркулярно-поляризованной люминесценции, точка Кюри слоя разбавленного магнитного полупроводника достигает $110 \mathrm{~K}$, что соответствует значениям для слоев (Ga,Mn)As, полученных методом молекулярнолучевой эпитаксии $[1,5]$. Различие между данными, полученными по гальваномагнитным измерениям и измерениям степени циркулярной поляризации (рис. 3 и 4), мы связываем с неоднородностью лазерного отжига по поверхности структур (как было показано на рис. 2). При гальваномагнитных исследованиях область, участвующая в измерении, составляет $\sim 4 \times 4 \mathrm{~mm}$ и включает как участок в центре лазерного пятна, так и на периферии. Можно предположить, что на изменение вида кривой магнетосопротивления оказывают влияние периферийные участки (Ga,Mn)As, значение температуры Кюри которых очевидно ниже, чем на участках, находящихся в центре лазерного пучка. При измерениях циркулярнополяризованной электролюминесценции был исследован диод, сформированный из центра структуры: для данной области интенсивность воздействия максимальная и значение температуры Кюри также, по-видимому, выше. С точки зрения наибольших достижимых значений рабочей температуры следует взять за основу именно данные по циркулярно-поляризованной люминесценции.

\section{4. Заключение}

Таким образом, в рамках настоящей работы был предложен новый способ повышения рабочей температуры спинового светоизлучающего диода, содержащего слои $(\mathrm{Ga}, \mathrm{Mn}) \mathrm{As}$, а именно - импульсный лазерный отжиг поверхности структур перед нанесением контакта. Гальваномагнитные исследования, как и исследования циркулярно-поляризованной люминесценции ССИД, показали, что в результате отжига происходит повышение температуры Кюри (Ga,Mn)As и увеличение рабочей температуры спинового светоизлучающего диода до значения $\sim 110 \mathrm{~K}$ (для исходной структуры таковое значение составляет $30 \mathrm{~K}$ ). Обнаруженный эффект связывается с влиянием импульсного лазерного воздействия на структуру слоев $(\mathrm{Ga}, \mathrm{Mn}) \mathrm{As}$, заключающимся в перестроении атомов $\mathrm{Mn}$ в положения замещения $\mathrm{Ga}$ и повышении концентрации дырок [4]. Полученные значения температуры соответствуют наилучшим показателям для структур, сформированных методом молекулярно-лучевой эпитаксии.

\section{Список литературы}

[1] D.K. Young, J.A. Gupta, E. Johnston-Halperin, R. Epstein, Y. Kato, D.D. Awschalom. Semicond. Sci. Tech. 17, 275 (2002).

[2] Е.И. Малышева, М.В. Дорохин, М.В. Ведь, А.В. Кудрин, А.В. Здоровейщев. ФТП 49, 1497 (2015). 
[3] Е.И. Малышева, М.В. Дорохин, А.В. Здоровейщев, М.В. Ведь. ФТТ 58, 2190 (2016).

[4] О.В. Вихрова, Ю.А. Данилов, Б.Н. Звонков, А.В. Здоровейщев, А.В. Кудрин, В.П. Лесников, А.В. Нежданов, С.А. Павлов, А.Е. Парафин, И.Ю. Пашенькин, С.М. Планкина. ФТТ 59, 2130 (2017).

[5] T. Jungwirth, J. Sinova, J. Masek, J. Kucera, A.H. MacDonald. Rev. Mod. Phys. 78, 809 (2006).

[6] Б.Н. Звонков, О.В. Вихрова, Ю.А. Данилов, Е.С. Демидов, П.Б. Демина, М.В. Дорохин, Ю.Н. Дроздов, В.В. Подольский, М.В. Сапожников. Опт. журн. 75 (6), 56 (2008).

[7] S. Zhou. J. Phys. D: Appl. Phys. 48, 263001 (2015).

[8] N. Nagaosa, J. Sinova, S. Onoda, A.H. MacDonald, N.P. Ong. Rev. Mod. Phys. 82, 1539 (2010).

Редактор К.В. Емиев 